Boston University School of Law

Scholarly Commons at Boston University School of Law

Faculty Scholarship

1999

The Last Resort: The Use of Physical Restraints in Medical

Emergencies

George J. Annas

Follow this and additional works at: https://scholarship.law.bu.edu/faculty_scholarship

Part of the Health Law and Policy Commons 
Legal Issues in Medicine

\section{The Last Resort - The Use of Physical Restraints in Medical EMERGENCIES}

\author{
GeORge J. ANNAS, J.D., M.P.H.
}

$\mathrm{P}$ UBLIC awareness of the use of restraints in medicine has been greatly heightened by a fivepart investigative series on physical restraints in psychiatric hospitals by the Hartford Courant and reaction to it by Connecticut's U.S. senators, Joseph Lieberman and Christopher Dodd. ${ }^{1}$ In October 1998 the Courant's 50-state survey identified 142 patients who had died while in restraints or seclusion in the past decade, and the total number is probably much higher. ${ }^{2}$ The newspaper advocated the need for national standards for the use of restraints, impartial oversight, and accountability "for behavior that is cruel and even criminal." The use of restraints for patients in nursing homes has long been seen as problematic, but concern about their use for patients in general hospitals and psychiatric hospitals had less illumination..$^{3-8}$ New federal regulations should change this.

\section{FEDERAL REGULATIONS REGARDING RESTRAINTS}

Work on new federal standards for patients' rights in the Medicaid and Medicare programs, including standards for the use of restraints, had been under way before the Hartford Courant series but was accelerated because of it. ${ }^{9}$ The new federal regulations, which were announced in July 1999 and which apply to all patients in hospitals that participate in the Medicare and Medicaid programs, include the following standard for the use of "restraint for acute medical and surgical care":

(1) The patient has the right to be free from restraints of any form that are not medically necessary or are used as a means of coercion, discipline, convenience, or retaliation by staff. . . . (2) A restraint can only be used if needed to improve the patient's well-being and less restrictive interventions have been determined to be ineffective. . . . (3) The use of restraint must be . . . in accordance with the order of a physician or other licensed independent practitioner [and] . . . never written as a standing [or as needed] order. . . . (4) The condition of the restrained patient must be continually assessed, monitored, and reevaluated. ${ }^{9}$

From the Health Law Department, Boston University School of Public Health, Boston.
There is a separate standard for the use of seclusion and restraints for behavior management. (Seclusion is not allowed at all under the standard for medical care.) This standard resembles the medical and surgical standard but is stricter, including provisions that "seclusion or restraint can only be used in emergency situations if needed to ensure the patient's physical safety and less restrictive interventions have been determined to be ineffective," that a "physician or other licensed independent practitioner must see [the patient] and evaluate the need for restraint or seclusion within 1 hour after the initiation of this intervention," and that orders must be written and must be "limited to [a period of] 4 hours for adults; 2 hours for children and adolescents ages 9 to 17 or 1 hour for patients under 9." Once the original order expires, a physician (or licensed independent practitioner, if permitted by state law) must see and assess the patient before a new order can be issued. ${ }^{9}$

Physical restraints include both mechanical devices and drugs used to "control behavior or to restrict the patient's freedom of movement." Staff members must be educated and trained in their use, and hospitals must report any deaths that occur while a patient is restrained or in seclusion to the Health Care Financing Administration (HCFA). ${ }^{9}$ The American Hospital Association had been on record as favoring putting "systems in place to prevent these deaths." The association, however, immediately went to court to enjoin enforcement of the regulations on restraints and seclusion, primarily on the basis that implementation would require additional staffing, especially with respect to the rule that patients who are restrained for behavior management must be seen by a physician within one hour. ${ }^{11}$ According to the American Hospital Association, hospitals would prefer to have physicians call in behavior-management orders and do not believe that physicians could be induced to come into the hospital in the middle of the night to perform the assessment as required by the regulations. The association's petition was properly rejected by U.S. District Court Judge Gladys Kessler. ${ }^{12}$

Nonetheless, there are problems with the new rules. The central one, I think, is that the rules do not make it clear enough that competent patients have a right to refuse any medical treatment and that the use of restraints can never be justified as a means of forcing treatment on a competent patient who is refusing treatment. A case decided in the spring of 1999 by the Massachusetts Supreme Judicial Court, which is not referred to in the new regulations, illustrates this and related issues. ${ }^{7}$

\section{RESTRAINTS IN THE EMERGENCY DEPARTMENT}

The facts of the case were summarized by the court as follows. Catherine Shine, the 29-year-old daughter of a physician, suffered a severe asthma attack on 
a Sunday morning in March 1990 while at her sister Anna's apartment (like the court, I use first names to distinguish the sisters). Catherine had had asthma most of her life and was well informed about her illness, which had been controlled by medication. Her attacks were characterized by a rapid onset and rapid remission. She had never required intubation. ${ }^{13}$

Anna suggested that they go to Massachusetts General Hospital. Catherine agreed, but only if her treatment would be limited to the administration of oxygen. Anna called the hospital and was assured that Catherine would be treated only with oxygen. They went to the emergency department at 7 a.m., where Catherine was given oxygen and medication through a nebulizer. Catherine soon removed the nebulizer, reporting that the medication gave her a headache, and said she wanted to leave the hospital. This behavior alarmed the treating nurse. Blood gas results, obtained at about 7:30 a.m., showed that she was "very sick." Dr. José Vega, the only attending physician on duty in the emergency department that morning, examined Catherine and concluded that intubation was necessary. Catherine refused, and Vega agreed to continue treatment with the oxygen mask. ${ }^{13}$ Anna meanwhile telephoned their father, Dr. Ian Shine, in England. Dr. Shine spoke with a physician and told him that Catherine understood her illness well and that he should listen to her and not treat her without her consent. Vega testified that he told Shine that he had to intubate Catherine because she was "in the midst of a severe asthma attack" and that Shine asked him to wait until he flew to Boston before attempting the intubation. ${ }^{13}$

When Anna returned to Catherine's room, she saw that her sister's condition had improved somewhat. Catherine was able to talk and breathe more easily, but she was in a heated argument with the staff. At about 7:40 a.m., when they were left alone for a moment, Catherine told Anna to "run"; they ran down the corridor to an exit door, where they were forcibly apprehended by a physician and a security guard. Catherine was returned to her room, and Vega immediately ordered her placed in four-point restraints. Anna was removed from the room and not allowed to speak with her sister or observe her treatment. At approximately 8 a.m., new blood gas results indicated that Catherine's condition had improved; Vega did not read the new test results and testified that they would not have affected his decision to intubate her in any case. ${ }^{13}$

At approximately 8:25 a.m., forcible intubation commenced. Catherine had been in four-point restraints for about 45 minutes. No one ever questioned Catherine's competence to consent to treatment, nor was there any basis to question her competence. Catherine never consented to intubation, and Vega testified that he never discussed the risks and benefits of intubation with Catherine, Anna, or their father. Cath- erine's condition subsequently improved, and she was released from the hospital the following day. ${ }^{13}$

\section{THE AFTERMATH OF EMERGENCY TREATMENT}

Evidence was presented at trial that Catherine had been severely traumatized by her mistreatment at the hospital. She had nightmares, cried constantly, was unable to return to work for several months, became obsessed about her medication, and swore repeatedly that she would never go to a hospital again. Approximately two years later, in July 1992, Catherine had a severe asthma attack while at home with her fiancé and her brother. She refused to be taken to the hospital. Her brother, nonetheless, called an ambulance after she became unconscious, which transported her to a nearby hospital. After unsuccessful medical treatment, she died.

Her father, as administrator of her estate, brought a multicount complaint against Vega and Massachusetts General Hospital, alleging, among other things, negligence, assault and battery, false imprisonment, and wrongful death. Her father's primary contention, both at the trial and on appeal, was that Vega wrongfully restrained and intubated Catherine without her consent. Vega and the hospital took the position that since Catherine had a life-threatening emergency, consent was not necessary. ${ }^{13}$ The trial judge, Margaret R. Hinkley, mistakenly instructed the jury that "under Massachusetts law a patient has the right to refuse medical treatment except in an emergency, life-threatening situation." 13 The jury returned a verdict in favor of the defendants on all counts. Catherine's father appealed. The Supreme Judicial Court took the case directly, and all seven justices, in a unanimous decision, vacated the judgment and remanded the case to the Superior Court for a new trial. ${ }^{13}$

\section{THE DECISION OF THE MASSACHUSETTS SUPREME JUDICIAL COURT}

The opinion, written by Justice Margaret Marshall, reviewed a number of the court's own precedents, which held that both common law and constitutional law provide for the "right of a competent individual to refuse medical treatment." 14,15 The court had previously explained that the "right to bodily integrity" had developed through the doctrine of informed consent under which "a physician has the duty to disclose to a competent adult sufficient information to enable the patient to make an informed judgment whether to give or withhold consent to a medical or surgical procedure." ${ }^{14,15}$ The patient's decision need not be a "wise" one, and the right to refuse treatment includes the right to refuse "lifesaving procedures." 14-16

This opinion simply restates well-established law, although the fact that the trial-court judge did not know the law is disturbing. Appeals courts, however, 
exist to correct such errors. The defendants had argued that there is an exception to the informed-consent doctrine in the case of lifesaving treatment rendered in an emergency department, which includes the use of restraints as part of treatment. The court was sympathetic to emergency department physicians but ruled that the need for quick action in an emergency cannot justify ignorance of the law or indifference to basic legal rights. In the words of the court:

If the patient is competent, an emergency physician must obtain her consent before providing treatment, even if the physician is persuaded that, without the treatment, the patient's life is threatened. If the patient's consent cannot be obtained because the patient is unconscious or otherwise incapable of consenting, the emergency physician should seek the consent of a family member if time and circumstances permit. ${ }^{13}$

The court also quoted a standard law textbook that summarizes the three basic requirements for emergency treatment without consent:

(a) The patient must be unconscious or without capacity to make a decision, while no one legally authorized to act as agent for the patient is available; (b) time must be of the essence, in the sense that it must reasonably appear that delay until such time as an effective consent could be obtained would subject the patient to a risk of serious bodily injury or death which prompt action would avoid; and (c) under the circumstances, a reasonable person would consent, and the probabilities are that the patient would consent. ${ }^{13,16}$

The defendants did not contend that Catherine was incompetent (i.e., not able to understand and appreciate the nature and consequences of her decisions) but rather that after she was prevented from leaving the hospital, she "became more confused and combative, refusing treatment." Her responses, however, were very reasonable in the light of the physician's actions and were not evidence of incompetence. An assessment of competence in this case required Catherine to answer only two questions: Did she know what the physician wanted to do and why? And did she know that she could die if the intervention was not performed? ${ }^{17,18}$ The answer to both these questions was indisputably yes. Of course, had it been determined that Catherine was incompetent, her sister and father would have had the authority to make decisions on her behalf consistent with her directions, not the physician alone.

\section{WOULD THE NEW RULES HAVE HELPED?}

There was no legal or ethical justification for the use of restraints in Catherine's case. But would the new federal regulations have helped, if they had been in place at the time? The regulations first require a determination of the reason for the use of restraints. Was restraint proposed for "acute medical care" or for "behavior management"? A case can be made for both classifications, raising the question of which set of regulations should have priority in a case like this (or even whether both sets must be followed in a mixed case). Because of the link between restraint and intubation, the strongest argument is that the restraint was used for the purpose of treatment. On the other hand, restraint was also used as a means of coercion - to prevent Catherine from leaving the hospital. The regulations do not make it clear enough that medical care is intended to promote the patient's overall well-being, whereas the goal of behavior management is only to prevent a patient from harming himself or herself ( such as by hitting his or her head against a wall or attempting suicide) or from harming others. Behavior management is closer to a policing function. The patient's primary protection against the use of restraints under the new regulations is the requirement of a physician's order. This, of course, offers no protection at all in a case in which the physician initiates the improper use of restraints.

Two other provisions might have helped Catherine. Four-point restraints are almost never the least restrictive means available, and the regulations require that the use of a restraint must be "selected only when other less restrictive measures have been found to be ineffective to protect the patient or others from harm." 9 Following this rule would have required at least a rational explanation (i.e., a discussion of informed consent), followed by the use of verbal threats and a show of physical intimidation (neither of which is acceptable in this case, but both of which would be "less restrictive") before the actual use of physical restraints. The regulations also require that the use of restraints be "ended at the earliest possible time." After Catherine's second blood gas test showed that her condition was improving, neither treatment nor restraints were necessary. The blood gas levels were not rechecked by the physician, but if the regulations had been followed, such a reassessment would have been necessary, since the regulations state that "the condition of the restrained patient must be continually assessed, monitored, and reevaluated."

As originally proposed, the rules included the phrase that restraints could be "used only as a last resort." A number of commentators suggested that this phrase be replaced with "when medically necessary." As the Massachusetts case illustrates, however, this phrase can make the decision to use restraints seem like a medical one. Catherine's physician might have thought that his use of restraints was "medically necessary." HCFA decided against the use of either phrase and instead replaced "as a last resort" with the phrase "when other less restrictive measures have been found to be ineffective." I think this was a mistake. HCFA was right not to see the use of restraints as a standard medical procedure, but the agency was wrong to back down. The overall point of the 
regulations is that restraints and seclusion are to be used only if absolutely necessary, and the language that best expresses this and alerts all staff members that the use of restraints should be unusual is that they should be used "only as a last resort."

\section{COMPETENT PATIENTS AND RESTRAINTS}

The only justification for the use of restraints in an emergency is to prevent patients from physically harming themselves or others, and even then they should be used only for the shortest time possible and with the least restriction possible. Even in the emergency setting, competent adult patients retain the right to refuse treatment. Coercive measures, including restraints and the threat of restraints, cannot be used simply because a patient refuses treatment.

It is never appropriate to restrain a competent patient against his or her will solely because he or she is refusing treatment recommended by a physician. Neither the law nor the new federal regulations if they had been in effect - permitted the use of restraints in Catherine Shine's case. It is, moreover, almost always the case in disputes between a physician and a competent patient over a recommended treatment, even in an emergency, that the most effective approach is to continue to discuss with the patient the reasons for the recommendation, the alternatives, and the consequences of doing nothing. This approach takes time, but there is no substitute. The patient's family is often useful in this situation, not because the family has any legal authority to consent on behalf of a competent patient, but because they might help the emergency physician understand the patient and might also help the patient understand the emergency physician.

It can also be very useful to contact the patient's primary care physician. On the other hand, communication by telephone can sometimes do more harm than good - since neither the person at Massachusetts General Hospital who assured Anna that Catherine would get only oxygen nor her physician father, who was in England, could properly assess Catherine's condition over the telephone. This is why the federal regulations properly insist on the actual presence of a physician. Continued discussion is important because a patient who understands the recommended intervention and its rationale is much more likely to agree to it. A refusal under these circumstances is more likely to be an informed one as well, and refusals as well as agreements to treatment must be informed. ${ }^{19}$ Competent patients, however, cannot be forced either to talk or to listen, and the fact that they will not talk to the physician does not by itself make them incompetent, any more than the fact that they do not agree with the physician's recommendation.

Catherine Shine, as a competent adult patient, also had a legal right to leave the hospital at any time she decided to leave. Hospitals are not prisons, and patients do not check their legal rights at the door when they enter, even when they enter through the emergency department. Catherine should have been allowed to leave the hospital because she was competent. In contrast, when Catherine's brother and fiancé brought her unconscious to the emergency department, the physicians there could (and did) properly treat her on the authorization of these persons. The only time emergency department physicians should not treat an unconscious patient is if the physicians know that the patient would not accept a particular treatment even if it was thought to be necessary to prevent death. This point would be difficult to prove, but if Catherine either had had a prior relationship with the physician or had completed an advance directive forbidding intubation under such circumstances, then her directive would have been legally decisive, not the wishes of her family.

The overarching general rule is that informed consent is required before physicians can lawfully treat competent adult patients, all of whom have the right to refuse any medical treatment. ${ }^{13,16-21}$ Patients who consent to interventions such as surgery, of course, agree to the reasonable use of drugs and physical restraints during surgery and postoperatively while they are disoriented. But in most other circumstances, few competent patients would agree to be restrained. Insofar as they continue the move away from paternalism to the protection of patients and their rights, the new HCFA regulations are to be applauded. However, the absence of a clear statement that they apply only to incompetent patients leaves the regulations open to potentially dangerous misinterpretation. And to the extent that they make the use of restraints seem legitimate and medically appropriate in some settings, they fall short of conveying the message that restraints should be used only as a last resort.

\section{REFERENCES}

1. A light in dark spaces. Hartford Courant. October 22, 1998:Al8.

2. Deadly restraint: how the Courant conducted its investigation. October 11, 1998:A12

3. Greenlaw J. Failure to use siderails: when is it negligence? Law Med Health Care 1982;10:125-8.

4. Parker K, Miles SH. Deaths caused by bedrails. J Am Geriatr Soc 1997; 45:797-802

5. Miles $\mathrm{SH}$, Irvine P. Deaths caused by physical restraints. Gerontologist 1992;32:762-6.

6. Evans LK, Strumpf NE. Tying down the elderly: a review of the literature on physical restraint. J Am Geriatr Soc 1989;37:65-74

7. Janelli LM. Physical restraint use in acute care settings. J Nurs Care Qual 1995;9(3):86-92.

8. Donat DC. Impact of a mandatory behavior consultation on seclusion/ restraint utilization in a psychiatric hospital. J Behav Ther Exp Psychiatry 1998;29(1):13-9.

9. Health Care Financing Administration, Department of Health and $\mathrm{Hu}$ man Services. Medicare and Medicaid programs: hospital conditions of participation, patients' rights. Fed Regist 1998;64(127):36070-89.

10. Weiss EM. Hundreds of the nation's most vulnerable have been killed by the system intended to care for them. Hartford Courant. October 11, 1998:Al.

11. Bowman C. AHA seeks to loosen restraint rules as attorneys warn of 
compliance problems. BNA's Health Law Reporter. August 26, 1999: 1405-6.

12. Weiss EM. Judge rejects delay in restraint law. Hartford Courant. July 31, 1999:Al4.

13. Shine v. Vega, 429 Mass. 456, 709 N.E.2d 58 (1999).

14. Norwood Hospital v. Munoz, 409 Mass. 116, 564 N.E.2d 1017

(1991).

15. Matter of Conroy, 98 N.J. 311, 486 A.2d 1209 (1985).

16. Prosser WL, Keeton WP. Torts. 5 th ed. St. Paul, Minn.: West Publishing, 1984:117.
17. Annas GJ, Densberger JE. Competence to refuse medical treatment: autonomy vs. paternalism. Toledo Law Rev 1984;15:561-89.

18. Lane v. Candura, 6 Mass. App. 377,376 N.E.2d 1232 (1978).

19. Truman v. Thomas, 27 Cal. $3 \mathrm{~d} 285$, 165 Cal. Rptr. 505,611 P. $2 \mathrm{~d}$ 902 (1980).

20. Washington v. Glucksberg, 521 U.S. 702 (1997).

21. Vacco v. Quill, 521 U.S. 793 (1997).

(C)1999, Massachusetts Medical Society. 